\title{
Undergraduate summer research in RF photonics
}

\section{Azad Siahmakoun, Galen Duree, Sergio Granieri, Bruce Black}

Azad Siahmakoun, Galen Duree, Sergio Granieri, Bruce Black,

"Undergraduate summer research in RF photonics," Proc. SPIE 9663, Eighth International Topical Meeting on Education and Training in Optics and

Photonics, 96632R (6 October 2003); doi: 10.1117/12.2208442

SPIE Event: Eighth International Topical Meeting on Education and Training in Optics and Photonics, 2003, Tucson, Arizona, United States 


\title{
Undergraduate Summer Research in RF Photonics
}

\author{
Azad Siahmakoun, Galen Duree, Sergio Granieri, and Bruce Black \\ Department of Physics and Optical Engineering, Rose-Hulman Institute of Technology, 5500 Wabash Ave., Terre Haute, Indiana, USA \\ Phone: 812877 8400, Fax: 812877 8023, E-mail:azad.siahmakoun@ rose-hulman.edu
}

\section{Summary}

Over the past four years, 2000-2003, undergraduates have participated in summer research at Rose-Hulman Institute of Technology (RHIT) carrying out a wide range of optics projects. These projects are supervised by an interdisciplinary group of faculty that includes professors from Physics and Optical Engineering, Electrical and Computer Engineering, Mathematics and Chemistry departments. This program was advertised by sending out flyers to 300+ collages and universities nationally. One-third of the students were from outside RHIT. Three of these students have subsequently become graduate students at RHIT. The program begins in the second week of June and lasts for ten weeks. It begins with an overview and description of the main goals of the optical beamforming project that is funded by NAVSEA Crane Division. Students are given a statement-of-work (SOW) and asked to reply to it in one week. During the first week students also participate in three short courses: Fiber Optics, Lasers and Detectors, Dynamic Range and Noise Figure in RF Links. The summer's work is structured and is done according to a schedule that is worked out between each team of students assigned to the specific task and their faculty advisor. Each team of students gives a weekly presentation to the group describing what was done during the week and what their plans are for the following week, thus constantly modifying their reply to the SOW based on what happens in the lab. The summer research program ends with a final project report and presentation given by each team of students. Students' projects have included a broad range of science and engineering areas varying from optics to electronics, optoelectronics, polymer chemistry. Some examples of these projects are: characterizing fiber-optic links, nonlinear optics, fixing volume holograms in photorefractive crystals, fabrication of fiber Bragg gratings (FBG), fiber-optic true-time delay architectures, simulation of fiber-optic networks for optical beamforming, construction of Optical beamformers based on FBG array matrix, fabrication of electro-optic polymer films. Some the projects have lead to student publications in peer reviewed and conference proceedings.
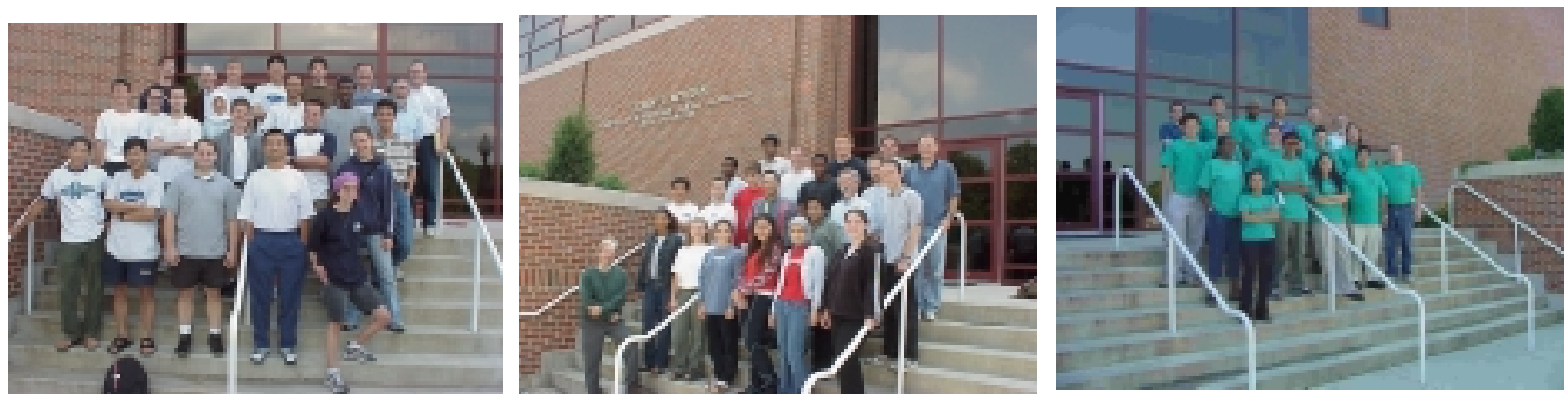

Figure 1. Photos of student and faculty groups that participated in the Summer Research Program 20002002 (left to right).

We will present some examples of the above projects. We will discuss the student learning that has taken place, both the successes and failures. Funding challenges and project costs will be presented. The impact of the summer program on other funded projects within the department will be discussed as well. The impact of the program on graduate student recruiting will be also be briefly discussed.

\section{References}

[1]. Sergio Granieri, Steven Hughes, Azad Siahmakoun, and Bruce Black" Optical Single Sideband Suppressed Carrier Modulation," Proc. SPIE, 4534, 155-161 (2001).

[2]. Bruce Black, Azad Siahmakoun, Laura Slaybaugh, Dean Thalen and Jeffrey A. Chestnut, " Componentlevel simulation of optical beamforming networks," Proc. SPIE, 4532, 494-499 (2001).

[3]. A. Thompson, N. Nazhestkina, A. Siahmakoun, G. Duree and N. Roesler, “ Effects of applied DC/AC fields in electrical fixing process with SBN:60,” Appl. Phys. B:Lasers and Optics, in press 2003. 